\title{
OP. CIT. LAS FUNCIONES RETÓRICAS DE LA CITACIÓN FILOSÓFICA
}

\author{
Juan Antonio GonzÁlez de Requena Farré* \\ doi:10.11144/Javeriana.uph31-62.opfr
}

\begin{abstract}
RESUMEN
Se suele reconocer cierto dialogismo en los momentos fundacionales de la filosofía occidental, y es posible vislumbrar variadas formas de intertextualidad en nuestra tradición filosófica. Pese a ciertas tentaciones monológicas, la filosofía no constituye un sistema auto-demostrativo; ha tejido sus textos mediante la citación de otras voces discursivas y a través de la invocación de palabras prestadas. Este artículo pretende realizar una panorámica discontinua de las funciones retóricas de la citación en diversos momentos de la filosofía occidental. La cita filosófica ha contribuido a la autorización de la palabra o a la constitución de repertorios discursivos compartidos $\mathrm{y}$, también, a la invocación intertextual de otras voces discursivas o a la integración de los textos ajenos en el metadiscurso del filósofo. Actualmente, la regulación disciplinar de las prácticas de citación y la economía bibliométrica de los índices de impacto pone en riesgo todo ese legado dialógico e intertextual.
\end{abstract}

Palabras clave: citación; dialogismo; intertextualidad; retórica; filosofía

\footnotetext{
*Universidad Austral de Chile, Sede Puerto Montt, Chile.

RECIBIDO: 18.10 .13

ACEPTADO: 15.12 .13

DiSPONIBLE EN LÍNEA: 30.06 .14

Para citar este artículo: González de Querra Farre, J.A. (2014). Op. Cit. Las funciones retóricas de la citación filosófica. Universitas Philosophica, 31(62), 15-39. ISSN 01205323; ISSN en línea 2346-2426; doi:10.11144/Javeriana.uph31-62.opfr
} 


\title{
OP. CIT. RHETORICAL FUNCTIONS OF PHILOSOPHICAL QUOTATION
}

\author{
Juan Antonio GonzÁlez de Requena FarRé
}

\begin{abstract}
Certain dialogism is generally recognized in the founding moments of Western philosophy, and it is possible to see various forms of intertextuality in our philosophical tradition. In spite of certain monological temptations, philosophy is not a self-demonstrative system; it has woven its texts quoting other discursive voices and through the invocation of borrowed words. This article aims to outline a discontinuous overview of quotation rhetorical functions at different moments of Western philosophy. The philosophical quote has contributed to discursive authorization or to provide shared discursive repertoires, but also to invocate other intertextual voices discursive or integrate other texts in the meta-discourse of the philosopher. Nowadays the disciplinary regulation of citation practices and the bibliometric economy of impact indices threaten that dialogic and intertextual legacy.
\end{abstract}

Key words: quotation; dialogism; intertextuality; rhetoric; philosophy 
No contentarse con un catálogo enciclopédico de los injertos (...), sino elaborar un tratado sistemático del injerto textual. Entre otras cosas, nos ayudaría a comprender el funcionamiento de una nota a pie de página, por ejemplo, así como un exergo, y en qué, para quien sabe leer, importan en ocasiones más que el texto llamado principal o capital.

(Derrida, 1975: 306).

Desde Que el Platonismo esbozó El IDEAl LÓGICO-RETóRICO de un discurso orgánico y que asiste a su propia verdad, la filosofía occidental ha consagrado frecuentemente cierta ilusión de un logos tan autónomo como autogenerado y autojustificado, que hallaría su máxima expresión en la apuesta por el sistema demostrado geométricamente. Se obliteraba así todo indicio discursivo de alteridad o de historicidad, todo aquello que insinuase la presencia de una palabra prestada, aun cuando la filosofía siempre desplegó su voz a través de un tenso diálogo con otros discursos socio-históricos y mediante una respuesta crítica hacia el legado de la propia tradición filosófica. Como contrapartida, la tradición retórica, con su énfasis en el carácter local y situado de las razones persuasivas y de los auditorios posibles, recogió en sus textos las voces de numerosos discursos contemporáneos o pasados, para esbozar modelos compartidos de desempeño retórico. En efecto, la retórica antigua recurrió a citas de toda índole para ilustrar los recursos del discurso convincente, pese a no reflexionar demasiado sobre la citación de discursos ajenos como elemento retórico crucial en el habla cotidiana y en la exposición textual del arte retórico.

Desde hace tiempo la filosofía cuestiona la clausura logocéntrica del discurso filosófico, y emprende una exploración tanto de las formas de envío que sostienen la palabra filosófica, cuanto de las modalidades de iteración citacional e injerto intertextual que exponen la exterioridad del discurso de la filosofía. Sin embargo, la Nueva Retórica contemporánea no parece haber desarrollado una reflexión suficiente sobre la eficacia retórica de la citación, a la que tanto recurre para inscribir ejemplos elocuentemente relevantes, a pesar de las emergentes formas de intertextualidad que caracterizan a las interacciones comunicativas actuales ${ }^{1}$. En ese sentido, parece oportuno

\footnotetext{
${ }^{1}$ Pese a la abrumadora cantidad de citas directas e indirectas, al cuidadoso aparato de citas a pie de página y a las casi quinientas obras citadas en su Tratado de la argumentación, Perelman y Olbrechts-Tyteca apenas se refieren en una ocasión al rol retórico de la cita. Esta
} 
realizar un análisis de las formas y funciones de la citación en el discurso filosófico, de manera que se pueda restablecer cierto diálogo entre la tradición retórica y la reflexión filosófica.

\section{Dialogismo, intertextualidad y citación}

A PESAR DE CIERTA TENTACIÓN MONOLÓGICA de algunas de nuestras tradiciones discursivas e intelectuales, no existe discurso que no reproduzca y acoja de alguna manera la palabra ajena, otras voces enunciativas y las entonaciones estilísticas de otros géneros discursivos. Al fin y al cabo, todo enunciado concreto constituye la respuesta activa a la interpelación de enunciados ajenos y anticipa la réplica discursiva de otros interlocutores, en una interacción comunicativa tan intersubjetiva como socio-históricamente enmarcada. Cada enunciación presupone una entonación discursiva que surge de la reacentuación de los acentos expresivos de otros géneros de discurso; en cada realización discursiva concreta de una voz singular resuenan otras voces (Voloshinov, 1976; Bajtín, 1982). Bajo el concepto de "dialogismo", el círculo de Bajtín enfatizó esta interanimación dialéctica del discurso; con los términos "polifonía" y "heteroglosia", expresó la presencia constante de la palabra ajena en toda enunciación y la tensión entre las diferentes acentuaciones socio-históricas que marca a toda voz discursiva (Ponzio, 1998; Brandist, 2002; Holquist, 2002)2 .

sería un tipo de enlace argumentativo que básicamente confirma lo enunciado mediante la apelación a una autoridad, aunque también puede constituir una figura de comunión, al procurar cierto reconocimiento, por parte del auditorio, en un repertorio discursivo compartido (Perelman y Olbrechts-Tyteca, 1989: 283-284).

${ }^{2}$ Desde la perspectiva del círculo bajtiniano, el discurso puede acoger otros enunciados y referir la palabra ajena en diferentes contextos, con variados propósitos y de distintas formas (Voloshinov, 1976). Según Voloshinov, se puede citar la palabra de otro para preservar dogmáticamente la homogeneidad discursiva y cierto estilo lineal, o bien para individualizar el discurso referido y someterlo a las réplicas del autor, o para distribuir voces singulares que desbordan el discurso del autor (Cfr. Voloshinov, 1976: 143-154). En ese sentido, es posible integrar el discurso del otro como una réplica imitativa del enunciado ajeno, una paráfrasis del tema, una representación del estilo de enunciación e, incluso, la inversión paródica de otro discurso. La palabra ajena puede aparecer referida literal y explícitamente en tanto que enunciado de otro, como un discurso directo; puede ser integrada en estilo indirecto, como una trasposición analítica de los enunciados; o puede incorporarse como un discurso cuasi-directo (en estilo indirecto libre o estilo representado), de manera que, al relatar lo acaecido, se recoja la voz expresiva de alguien y su discurso experimentado, pero con la construcción y perspectiva gramatical del autor del relato (Voloshinov, 1976: 164-194). 
En el contexto de la crítica literaria postestructuralista, las nociones bajtinianas de dialogismo y polifonía fueron invocadas, no tanto para remarcar el aspecto intersubjetivo de la enunciación y la singularidad de las voces discursivas concretas, sino con el propósito de cuestionar todo intento de clausurar -como conjunto único de sentido u obra dependiente de un autor- la productividad incontenible de la escritura literaria y la apertura inagotable de las remisiones textuales en el proceso de la lectura. Kristeva (1981) convocó a Bajtín para reiterar que todo texto acoge y transforma otros textos, conformando así un mosaico dialógico de citas y una escritura ambivalente, que inserta al texto en la historia e inscribe la historia en el texto. Desde la perspectiva de Kristeva, el discurso literario no consiste en un ámbito de sentido fijo, sino en un entrecruzamiento de los textos y escrituras del escritor, del destinatario, así como de diferentes textos culturales o de contextos y corpus textuales socio-históricos. De ese modo, la intertextualidad, el desbordante cruce productivo de textos en que se leen otros textos, reemplazó a la intersubjetividad bajtiniana en la teoría literaria postestructuralista (Kristeva, 1981: 188-190) ${ }^{3}$.

\footnotetext{
${ }^{3}$ La discusión sobre la intertextualidad perdura hasta el día de hoy en el ámbito de la teoría literaria y los estudios culturales. Barthes (1994) apeló a la intertextualidad para remarcar la dispersión de lenguajes socio-históricos y la proliferación de citas textuales anónimas, que concurren en todo texto y hacen posible la productividad textual de la escritura literaria. Para Barthes, el escrito no consiste en un ámbito lineal de sentido que remita a la autoridad del autor; todo texto constituye una red multiforme de escrituras y múltiples citas culturales en que resuenan, dialogan y se contestan, sin otro horizonte de integración que el lector, quien asume la labor de atar todos esos cabos textuales. Así, pues, la intertextualidad atraviesa todo texto, siempre entretejido con citas y resonancias de todo tipo de lenguajes culturales, sin que se pueda buscar una fuente originaria o un autor original (Cfr. Barthes, 1994: 6978). En ese sentido, la crítica literaria postestructuralista designó como intertextualidad una particular paradoja de los sistemas discursivos, esto es, el hecho de que textos y enunciados nunca constituyan momentos originarios, pues remiten a la existencia previa de todo un espacio discursivo de convenciones, pretextos, códigos culturales, prácticas enunciativas y operaciones interpretativas (Culler, 1976). De ahí que la intertextualidad resultase crucial a la hora de desmitificar la idea del texto como artefacto autónomo. Como argumentó Culler (1976), la intertextualidad permite concebir el texto como un diálogo con otros textos, su absorción o parodia; patentiza el artificio literario, las convenciones y operaciones interpretativas que sostienen toda escritura o lectura; además, pone en suspenso la referencia al mundo de la obra literaria, al entenderla como el comentario de otros textos. Con todo, la intertextualidad no designa tanto la búsqueda de fuentes u obras precursoras, cuanto patentiza todo un complejo espacio discursivo; no solo involucra las presuposiciones y pretextos de un texto, sino las presuposiciones pragmáticas y retóricas, así como las convenciones y operaciones interpretativas que enmarcan las prácticas discursivas (Culler, 1976). En el escenario intelectual contemporáneo, la perspectiva de
} 
Dentro del ámbito de la intertextualidad realizada en el discurso escrito, la citación textual (de fuentes, autores y obras) desempeña un papel crucial entre las formas de referencia de la palabra ajena. Se trata de una modalidad intertextual de discurso referido, que permite integrar en estilo directo o indirecto la palabra del otro, obien resumir, parafraseare, incluso, simplemente mencionar alguna fuente. Ahora bien, la cita adoptó su forma específica sobre el trasfondo socio-histórico específico de ciertas modificaciones en los canales de circulación del saber y en las tecnologías de comunicación, que introdujeron nuevas formas de incorporar la palabra de otros en el texto y nuevos usos del discurso ajeno. Solo tras la revolución de la imprenta en la Europa moderna se sistematizó y estandarizó progresivamente el empleo de signos de puntuación y recursos gráficos (como las comillas, los guiones, la cursiva o las notas al pie de página) para indicar la inserción de discurso ajeno dentro de algún lugar preciso del texto, así como se diversificaron los verbos realizativos que permitían referir la palabra ajena y las actitudes de los hablantes (Finnegan, 2011; Olson, 1999). En todo caso, el afianzamiento de los sistemas de integración del discurso referido resulta inseparable de toda una gama de usos retóricos de la citación de la voz ajena en variados universos intelectuales y contextos socio-históricos, como han puesto de manifiesto el libro de Grafton (1999) sobre la historia de la nota a pie de página o el artículo de Connors (1998) sobre la historia de los sistemas de citación ${ }^{4}$.

la intertextualidad está tan consolidada, que -según Allen (2000)- parece constituir una de las nociones centrales de los actuales lenguajes y discusiones culturales. A través de la intertextualidad se sigue impugnando la ilusión del significado textual independiente y de la obra autónoma. Al fin y al cabo, tanto la escritura como la lectura nos exponen a toda una red de relaciones textuales y nos incitan a explorar el nexo entre textos, ya se trate de la diseminación de los significantes textuales, de la relación intertextual entre éstos y textos culturales, del nexo entre textos y sistemas literarios o de las transformaciones entre textos. En un ámbito intelectual a veces llamado posmoderno, la intertextualidad introduciría así cierta perspectiva del carácter relacional e interconectado de la forma de vida moderna, sin que se pueda seguir apelando a la unicidad de sentido del texto o a la originalidad de la obra literaria (Cfr. Allen, 2000: 2-6).

${ }^{4}$ A través de la profusa citación, los humanistas del Renacimiento integraron comentarios, glosas y notas relativas a las fuentes clásicas, y así se acreditaron como parte de la comunidad de los eruditos. Por otra parte, a través de las glosas y los comentarios, de las citas y las referencias textuales, las iglesias católica y reformada continuaron su pugna religiosa por otros medios: a través de la discusión sobre las interpretaciones correctas de las escrituras y de la integración de una comunidad discursiva gracias a la autorización canónica del libro y de la exclusión del discurso herético. También entre los propulsores 
Como puede apreciarse, el creciente interés por la citación en el pensamiento contemporáneo trasciende los aspectos meramente gramaticales y semánticos relativos a la forma estructural o el significado referencial de la cita, que tanta atención recibieron por parte de la filosofía analítica, desde Frege (1984) hasta Davidson $(2001)^{5}$. Actualmente, la problemática filosófica

de la nueva ciencia y entre los intelectuales de la República Ilustrada de las Letras, la cita se convirtió en un recurso retórico clave para aportar evidencia, acreditar los argumentos planteados y realizar la crítica de las fuentes, de manera que en el siglo XVIII encontramos un amplio uso de las notas a pie de página que refieren y comentan críticamente el discurso ajeno. Sin embargo, solo en el curso del siglo XIX y a comienzos del XX, en el marco intelectual forjado por las metodologías de investigación de las ciencias del espíritu y de la historiografía alemana, pero también en el contexto de la extensión del acceso público a archivos estatales y bibliotecas, se profesionalizarían y formalizarían los sistemas de citación, hasta que finalmente se regularon las formas de citación del discurso ajeno y se codificaron en diferentes manuales de estilo (como el de la Universidad de Chicago o el de la American Psychological Association) (Connors, 1998). En todo caso, tampoco la cita formalizada y profesionalizada carece de efectos retóricos, ya que enmarca la experiencia de lectura (ya sea con una propuesta lineal de texto sembrado de referencias entre paréntesis, o con una invitación disruptiva a explorar un paratexto ubicado a pie de página), suministra un estratégico instrumento de persuasión (ya sea mediante la autorización con fuentes canónicas o de la indicación de evidencia reciente y novedosa), e incluye a los autores y a los lectores en comunidades discursivas de investigación (tanto a través del ritual cortés de identificación con los pares, como mediante la exclusión de quienes no manejan las referencias disciplinares obligadas) (Connors, 1999; Gilbert, 1977; Rose, 1996).

${ }^{5}$ Respecto a la semántica de la cita, en el contexto de la filosofía del lenguaje analítica se ha desarrollado una discusión bastante técnica acerca de la referencia de las citas directas entrecomilladas y de las expresiones en estilo indirecto. Desde que Frege estableció la distinción entre la referencia (lo designado) y el sentido (el modo de darse la designación), se ha planteado la posibilidad de que, además de usar las palabras de modo habitual y hablar de la referencia, se pueda hablar de las palabras mismas o de su sentido, como ocurre al citar palabras ajenas. Según Frege, cuando se citan las palabras de otro en estilo directo, la expresión entrecomillada no tiene su referencia habitual, pues se trata únicamente de signos de signos. Asimismo, al introducir palabras ajenas en estilo indirecto, las palabras no tienen su referencia usual, sino una referencia indirecta que consiste en el sentido habitual del discurso de otro (Cfr. Frege, 1984: 55). Frege concluye que, a diferencia de los enunciados que tienen como referencia su verdad o falsedad, los enunciados en estilo indirecto se refieren a otros enunciados, y las citas en estilo directo se refieren a cierto sentido; este tipo de enunciados subordinados incrustados en otra estructura enunciativa pueden concebirse incluso como un nombre propio de la expresión o el sentido que designan dentro del enunciado principal (Cfr. Frege, 1984: 65-70). Posteriormente, Goodman argumentó que la cita directa no solo nombra la expresión referida, sino que además contiene una réplica sintáctica de la expresión citada; por su parte, la cita indirecta ni nombra ni contiene la expresión referida, pues formula una paráfrasis semántica de lo 
de la citación comprende asuntos relativos a la posibilidad estructural de cualquier discurso o a los modos de presentación intencional que caracterizan al pensamiento humano en general. En ese sentido, Derrida ha radicalizado la concepción de la intertextualidad del discurso hasta tal punto que hace de la escritura y de la lectura una interminable labor de envío a otros textos, una prolífica tarea de re-acoplamiento de injertos textuales de todo tipo; como si se tratara únicamente de entretejer ilimitadamente significantes (inter-)textuales carentes de referencia presente y fija, sin posibilidad de reapropiación de un sentido textual clausurado. Para este tipo de lecturaescritura deconstructiva, toda forma de discurso constituye algún tipo de injerto que remite una y otra vez a otros textos e intertextos, de manera que

citado. De ese modo, Goodman propuso un modelo semántico general de la citación verbal basado en las condiciones de denotación e inclusión, que cubre tanto la cita directa como la indirecta: se requiere que lo citado (o alguna paráfrasis o réplica suya) se contenga en la cita; es condición necesaria que exista una referencia a lo citado, ya sea al nombrarlo o al predicarlo; pero, además, se supone que la sustitución de la expresión citada directamente, por otra expresión lingüística, genera una cita diferente (Cfr. Goodman, 1990: 67-74).

En un célebre artículo sobre la citación, Davidson (2001: 95-107) recapituló críticamente las posiciones sobre la cita en la filosofía analítica. Frente a la teoría de que la cita constituye un nombre propio o término singular global que denota la expresión citada, cabe argumentar que ese punto de vista no explica el funcionamiento de la cita en el lenguaje natural: la cita designaría tan arbitrariamente como los nombres propios, sin ilustrar su relación con lo citado, y no se daría cuenta de la posibilidad de generar nuevas citas. Ante la teoría pictórica de la cita, que resalta el modo en que el expresión entrecomillada ilustra lo citado (siendo las comillas el marco de esa relación figurativa), Davidson objeta que de ese modo la expresión citada se referiría trivialmente a sí misma, se daría una autorreferencia y no explicaría la forma generativa de la citación. Contra la teoría que considera la cita como una descripción complejamente estructurada que dé cuenta de la expresión referida, se puede sostener que esta tampoco da cuenta de la generatividad de la citación ni del modo en que la cita permite forjar un sinnúmero de expresiones ilustrativas en el lenguaje natural. En ese sentido, Davidson introduce una teoría de la cita que, además de preservar la referencia veritativa, pretende introducir una regla semántica del funcionamiento de los recursos para citar (como las comillas) y una explicación de las posibilidades generativas de la citación. Según la teoría demostrativa de la citación que Davidson propone, la expresión entre comillas constituye una inscripción que no tiene referencia alguna; son las comillas las que posibilitan la eficacia de la cita, al señalar un tipo de expresión del cual la expresión entrecomillada es una instancia singular, o mostrar una expresión con la forma ilustrada en el material citado (Davidson, 2001). En suma, podríamos considerar que la teoría de Davidson se centra en una de las posibilidades semánticas de la cita (mostrar un tipo formal a través de una instancia particular), en tanto que las otras teorías de la cita consideran otras opciones semánticas: que la cita muestre otra instancia mediante una instancia singular (teoría pictórica); que refiera un tipo estructural mediante una instancia particular (teoría 
los textos no dejan de proliferar, irradiar, expropiarse, contaminarse y desarticularse, en una intertextualidad sin reserva de sentido ni raíz originaria (Cfr. Derrida, 1975: 533-535). Desde esa perspectiva, no solo la escritura, sino también la posibilidad del discurso y de la semiosis, se sostendrían en el carácter repetible o iterable de las marcas significantes, en constante ruptura con todo contexto cerrado y en ausencia de alguna fuente intencional del sentido. No hay discurso, pues, que no esté marcado por esta radical iterabilidad y citacionalidad de las marcas textuales, que hace de la cita una modificación específica de la condición estructural de toda enunciación, a saber: poder ser citada reiteradamente y repetir parasitariamente otros textos en una deriva intertextual incalculable (Cfr. Derrida, 1989: 356-362).

En todo caso, no resulta obvio que la citación sea simplemente un asunto de repetición intertextual. Como Sokolowski (1984) ha argumentado, desde una perspectiva fenomenológica, la citación involucra la representación de lo que ha sido dicho por otras personas, de manera que presupone la capacidad de duplicación representacional y, además, de estados intencionales. Así, pues, la cita no consiste tanto en una estructura gramatical o semántica, sino en la expresión de una diferencia en los modos de mención intencional y en la presentación de lo dado. Según Sokolowski, al citar se usa una frase para

descriptiva), o que refiera una instancia particular mediante una instancia singular (teoría del nombre propio). Sea como sea, estos acercamientos semánticos a la citación suelen plantear el problema de que generalizan algún aspecto referencial de la referencia a partir de ejemplos particulares de cita (en especial, de la cita directa encerrada entre comillas y semánticamente aislada del enunciado que la contiene), en vez de considerar los usos específicos de la citación y las condiciones pragmáticas del empleo de los distintos tipos de cita (Recanati, 2001).

En ese sentido, los estudios del discurso citacional han puesto de manifiesto toda una pragmática de la cita, esto es, los repertorios de funciones que la cita puede desempeñar en la interacción comunicativa. A veces, las citas sirven para confirmar y desarrollar orgánicamente la argumentación del texto; otras veces recogen planteamientos alternativos a los del texto; frecuentemente, indican superficialmente alguna fuente de información o referencia textual adicional; no muy a menudo introducen una perspectiva negativa o crítica entre el pretexto y el texto que lo cita (Swales, 1986). Siguiendo a Morawski, Plett (1991: 13-15) propone distinguir cuatro modos funcionales de la cita, a saber: la cita que autoriza al enunciador y provee autoridad, a veces en contextos discursivos altamente ritualizados o ideológicos; la cita erudita, que aporta argumentos falibles en un contexto discursivo de discusión científica o intelectual; la cita ornamental, que embellece el texto para deleite estético del receptor; finalmente, la cita poética, la citación carente de propósito práctico y realizada tan solo para la reinvención ficcional de los universos de discurso textuales. 
referir un enunciado ajeno, y se marca la diferencia entre mi enunciación y el discurso del otro, de manera que podemos articular cómo se hace presente lo dado para otras personas e introducir la perspectiva intencional de otro hablante. De ahí que la citación ponga de manifiesto todo un abanico de modificaciones dóxicas, dependiendo de la posición y distancia que mantengamos frente a la voz ajena, ya se trate de la creencia, la duda, la seguridad, la probabilidad, la certeza, la sospecha o, incluso, la neutralidad. Además, según Sokolowski el modo en que los discursos ajenos se entretejen en nuestro discurso comprende complejas modalidades argumentativas que van desde la autorización o la tematización, hasta la recreación o la crítica. Sokolowski no solo entiende la citación como parte de nuestros estados intencionales y de nuestras conversaciones cotidianas, esto es, como una manera de verificar y triangular lo que se dice que hay; también, considera que existe un uso específicamente filosófico de la citación (comparable con la puesta entre paréntesis fenomenológica), en virtud del cual se pone en suspenso tanto lo que otros discursos dicen, cuanto el trasfondo cotidiano de la enunciación, las pretensiones de verdad comunes e, incluso, a los mismos interlocutores y su contexto. He ahí la radicalidad de la citación filosófica, que permitiría poner de manifiesto la heterogeneidad de las voces conversacionales y articular los marcos de nuestras conversaciones y discursos (Sokolowski, 1984). Pero, ¿hasta qué punto la filosofía occidental se aproxima a este horizonte ideal de una citación que patentiza la heterogeneidad de los discursos y articula los diversos modos de presentación de lo que hay?

\section{Las transformaciones retóricas de la cita filosófica}

Ciertamente, el discurso de la filosofía occidental conformó su canon fundacional a través de la exploración de la forma dialogada de los textos platónicos. Bajo esta disposición dialógica, las razones y pretensiones de validez se incorporaron en las interpelaciones de personajes que encarnaban diferentes voces y discursos tanto de las tradiciones griegas, como del espacio público de la polis. En efecto, los diálogos platónicos ponen en escena un repertorio heterogéneo de voces que hablan directamente, se dan la palabra y se interpelan recíprocamente; aunque, con frecuencia, los interlocutores también recitan y leen discursos de otros, recuerdan con sus propias palabras las palabras ajenas, o parafrasean relatos y narraciones compartidas. No resulta extraño, pues, que se haya considerado a los diálogos platónicos una realización ejemplar de un dialogismo radical, que patentizaría la pluralidad 
de las voces conversacionales y, al mismo tiempo, articularía la diferencia dialógica que sostiene nuestras conversaciones. Sin embargo, en ese modelo de la filosofía occidental que son los diálogos platónicos también se esboza el ideal lógico-retórico de un discurso orgánico, lógicamente ordenado, concordante consigo mismo, y que asiste a su propia verdad en la medida en que es capaz de defenderse a sí mismo (Platón, 1985: 264b-277c). Desde entonces, parece que la filosofia occidental ha apostado por un estilo intelectual marcadamente monológico en que se insinúa cierta preferencia por el sistema, ya sea bajo la figura de la unificación dialéctica de lo múltiple bajo la idea, ya se trate de la jerarquización analógica de las categorías, o de la fundamentación lógica de lo particular a partir de principios universales, o de la ordenación metodológica del conjunto de los saberes y de la integración axiomática de los diferentes conocimientos, o bien de la exposición sistemática de la totalidad orgánica de los momentos del saber. Sin embargo, por más que pretenda borrar las diferencias discursivas, el aspecto agonista de la enunciación y la heterogeneidad de las voces en el seno de su propio sistema, el discurso filosófico nunca logra eliminar completamente las huellas de la palabra ajena, que resulta convocada como cita, repetida como consigna, recitada como ejemplo y conjurada como pretexto.

Si revisamos uno de los momentos inaugurales de la sistematización onto-teológica del pensar occidental, a saber, la aporética apuesta de Aristóteles por intentar la fundamentación de una ciencia universal de los primeros principios y causas del ser en tanto que ser, nos queda claro que el estagirita, pese a privilegiar la unidad orgánica del saber lógicamente demostrable, no pudo dejar de invocar los heterogéneos discursos de otros filósofos anteriores. En efecto, el libro primero de la Metafisica aparece tapizado de referencias a los primeros filósofos y de citas de las opiniones de otros pensadores, que Aristóteles revisa críticamente. En ese contexto, la mayoría de las citas parece ser paráfrasis proposicionales y en estilo indirecto, que recoge los discursos de otros pensadores; aunque, eventualmente, se introducen referencias directas de algunos fragmentos de los enunciados de los filósofos anteriores (dos veces se cita directamente a Parménides, una a Simónides y a Hesíodo). Tan solo en el libro primero, Aristóteles cita indirectamente a Polo, Simónides, Anaxímenes, Diógenes, Hípaso, Heráclito, Empédocles, Anaxágoras, Parménides, Hermotimo, Hesíodo, Leucipo, Demócrito, Pitágoras, Alcmeón, Jenófanes, Meliso, Platón, Cratilo, Sócrates, Eudoxio e, incluso, se auto-cita al referirse a otros escritos de su autoría. De ese modo, se convoca en estilo indirecto a veintidós 
voces en tan solo uno de los catorce libros que comprende la Metafisica (una cifra relevante, si comparamos con los treinta y seis nombres citados en toda la Crítica de la Razón Pura de Kant). Las citas aristotélicas cumplen una función básicamente argumentativa y crítica, pues el autor expone con sus propias palabras puntos de vista teóricos ajenos, para cuestionar sus limitaciones y justificar la pertinencia de su propia empresa intelectual. Cabe pensar que la función de estas citas en estilo indirecto es más metadiscursiva que intertextual, pues tiene como propósito definir la posición del autor frente a lo enunciado y anticipar determinada recepción crítica de los lectores. Por otra parte, Aristóteles realiza un tipo de citación que parece cumplir cierta función comunicante en la medida en que la referencia a otros pensadores promueve un efecto de reconocimiento y cierta comunión intelectual en torno al trasfondo compartido de una creciente comunidad filosófica. En última instancia, Aristóteles sistematiza los argumentos ajenos planteados a través de la historia de la filosofía griega, y expone críticamente las contradicciones y tensiones de otras propuestas filosóficas. Pero, aunque Aristóteles remarca las aporías suscitadas por los problemas filosóficos que convocan a diferentes pensadores, los otros discursos filosóficos se citan como momentos unilaterales de una exposición que ya esboza el ideal del sistema y la integración de los distintos puntos de vista en un conjunto teórico orgánico.

Resulta interesante comparar este formato de citación con el que Aristóteles emplea en el libro segundo de la Retórica. Tan solo en el capítulo veintitrés, se realizan treinta y ocho citas directas y aproximadamente veintidós citas indirectas (solo las referencias indirectas igualan el número de voces incorporadas en todo el libro primero de la Metafisica). Se trata de voces bastante heterogéneas que corresponden a poetas y trágicos más o menos conocidos, pero también a personajes literarios y anónimos del mundo griego. Así, pues, en la Retórica encontramos un tipo de citación más preocupado de la reproducción lingüística, que de la paráfrasis proposicional. Se trata de un tipo de citación con un marcado carácter intertextual, ya que acoge en el texto otras voces discursivas locales y diferentes textos y argumentos socio-históricos. Además, las citas de la Retórica tienen un sentido primordialmente ilustrativo y figurativo, pues la citación se enfoca en ejemplificar la textura singular de la expresión citada y poner de relieve la propia cualidad estilística del discurso convocado. En lugar de introducir argumentativamente otras pretensiones filosóficas que haya que someter a crítica para integrarlas en la sistematización teórica, las citas de la Retórica 
aportan un tipo de evidencia ilustrativa, un variado repertorio de ejemplos singulares, una multitud de voces y estrategias enunciativas que escapan a la homogeneización en algún sistema. De ese modo, las citas retóricas no solo desempeñan la función de patentizar cierto trasfondo enciclopédico común desde el cual Aristóteles puede entenderse con sus lectores, sino que fundamentalmente constituyen un ejercicio de ejemplificación en que el autor del texto orienta al auditorio con alguna instancia singular que contiene su propia regla. No deja de ser curioso que, a pesar del importante rol retórico que cumplen las citas en este tratado de Aristóteles, no se les haya prestado mayor atención como recurso persuasivo, salvo algunas referencias al limitado papel de los testimonios y los relatos ejemplares (como elementos discursivos que procuran una ejemplificación singular de los argumentos), o de los adagios y las sentencias (como lugares comunes generales que facilitan cierta comunión con el auditorio). Posteriormente, las Instituciones oratorias de Quintiliano recomendarían citar los mejores discursos de otros y los testimonios ajenos, como una manera de aportar autoridad a lo que se alega; también se invita a recitar versos de los antiguos poetas, para lograr estilizar el discurso con gracia y erudición y para producir deleite estético en el auditorio (Cfr. Quintiliano, 1916: 40, 91). Esta limitada reflexión sobre la cita parece haber marcado a gran parte de la tradición retórica, que apenas prestó atención a la eficacia persuasiva de uno de los principales recursos de la propia exposición retórica. Aparentemente, la tradición retórica le ha dado más peso al carácter dirigido de todo discurso persuasivo (siempre intencionalmente enfocado en un auditorio específico), que al aspecto receptivo y citacional de toda enunciación.

En el caso de la tradición filosófica, las prácticas de citación se fueron modificando en la misma medida en que cambiaron las funciones retóricas de la cita. En los escritos de la escolástica medieval vemos irrumpir una mayor frecuencia de citas que en algunos escritos antiguos, tal vez como consecuencia de la generalización de una modalidad de escritura y de lectura que giraba en torno a la glosa y comentario de las sagradas escrituras y de las autoridades de la Iglesia. Los textos de San Buenaventura, de Santo Tomás de Aquino o de Duns Scoto introducen frecuentemente citas directas de la Biblia, así como citas directas o indirectas de los padres y doctores de la Iglesia (particularmente de San Agustín y San Anselmo) o de algunos filósofos antiguos (en especial, Aristóteles o sus comentadores árabes, como Avicena). A diferencia de las citas bíblicas, que reproducen literalmente el discurso consagrado y muestran la textura única de la palabra de Dios, las 
citas que recogen opiniones de filósofos o teólogos pueden parafrasear en estilo indirecto las proposiciones citadas. Las citas escolásticas aparecen al comienzo de alguna colación, en el punto de partida de algún comentario o en el curso de algunas cuestiones disputadas, como un capital simbólico o garantía interpretativa que el texto administra convenientemente, para autorizar los argumentos del autor y hacer que la obra participe de cierto canon de autoridades reconocidas. Al introducir comentarios y glosas autorizadores, la cita parece desempeñar una función marcadamente metadiscursiva, pues posiciona al enunciador frente a lo dicho y enmarca las posibles interpretaciones de los lectores. De ese modo, la eficacia retórica de la cita escolástica no solo reforzó en nuestra tradición filosófica la idea de que los argumentos se confirman por autoridades, sino que además estableció un tipo de escritura y de lectura que neutraliza la heterogeneidad de las voces discursivas, al promover el inagotable comentario de una palabra consagrada en el Libro sagrado o la glosa inacabable de algunas obras canónicas.

En el discurso filosófico de la primera modernidad se entrecruzan distintas prácticas de citación, cada una de las cuales le asigna a la cita un estatuto argumentativo específico y funciones retóricas determinadas. Por una parte, en un momento histórico en el que comienzan a multiplicarse los volúmenes de los libros y las obras publicadas gracias a la revolución de la imprenta, asistimos al despliegue de una profusión incontrolable de referencias intertextuales y a la multiplicación de las citas de fuentes de todo tipo. Se trata de un modo de citación desmesurado y a menudo delirante que, sobre todo en el ámbito de las filosofias naturales, incluye referencias clásicas y escolásticas, teóricas y poéticas, médicas y astrológicas, en universos de discurso donde las analogías y semejanzas simbólicas parecen enmarcar la construcción retórica del conocimiento. En la Anatomía de la melancolía de Robert Burton puede reconocerse este despropósito de una citación bibliográficamente informada, pero que da pie a todo tipo de digresiones erráticas. En cierto sentido, la delirante citación en la Anatomía de la melancolía puede interpretarse como un síntoma del extravío melancólico con que el autor lidia en su libro; al fin y al cabo, como Burton nos recuerda en una de las secciones de su obra, el exceso en la lectura y el estudio, así como el extravío libresco, constituyen una de las posibles causas de la melancolía profunda y de la locura del mundo (Cfr. Burton, 2008: 145182). Burton tapiza cada sección de su extraña obra con una multitud de citas directas e indirectas, que especifican cuidadosamente la fuente, el autor, la sección y página del documento en que se encuentra la cita. En el cuerpo 
del texto, pero también en cientos de notas numeradas, se cita un catálogo bibliográfico de lo más dispar, en el que se hacen presentes un sinnúmero de obras clásicas, escolásticas y contemporáneas de todo tipo (literarias, filosóficas, religiosas, científicas, médicas, astrológicas, mágicas, etc.). De ese modo, la cita no se limita a realizar la confirmación por autoridad, sino que introduce toda una constelación de esos nuevos descubrimientos, saberes renovados y perspectivas emergentes, que se abrieron camino con el desarrollo de la revolución científica y la erosión del saber escolástico. La exuberante citación de Burton tampoco parece introducir un marco enciclopédico compartido que pudiera generar un reconocimiento del lector en algún tipo de comunidad interpretativa; más bien, aglutina pretextos de las más heterogéneas procedencias en un crisol intertextual que provoca un marcado efecto de extrañamiento y de permanente difracción del sentido textual. De esa manera, la citación bibliográficamente descontrolada de Burton responde a una eficacia intertextual en estado prácticamente puro, que lleva al paroxismo la incorporación de otras voces discursivas y textos socio-históricos en una escritura repleta de correspondencias y desvíos; aunque también hace posible que cada uno de los fragmentos del abigarrado crisol intertextual brille con luz propia y exhiba su textura singular en el contexto de una extraña historia natural del desvarío.

Por otra parte, en el discurso filosófico de la primera modernidad vemos cómo se consolida un estilo arquitectónico o geométrico de argumentación filosófica, que apuesta por la demostración rigurosa a partir de principios evidentes y cimientos firmes, sin tomar en cuenta aquellas voces filosóficas o tradicionales que pudieran resultar dudosas. Esta retórica geométricamente modelada se enmarca en ese orden representacional analítico de la episteme de la época clásica, centrado en el cálculo racional de identidades y diferencias, que -según Foucault (1985)- puso límites al pensamiento analógico renacentista, basado en la exégesis de las semejanzas y las correspondencias simbólicas. El Discurso del método cartesiano expone ese estilo altamente mono-lógico e, incluso, auto-lógico, en virtud del cual la argumentación no puede contener nada que no se pueda demostrar con absoluta evidencia a partir del propio entendimiento racional. Las referencias letradas, la invocación de palabras ajenas o la apelación a autoridades tradicionales no valen prácticamente nada para este nuevo modo de argumentación filosófica, que recela de todo aquello que el razonamiento no conciba a partir de sí mismo con claridad y distinción. Para Descartes (1984), carece de sentido extraviarse en los discursos heredados, en las tradiciones de diferentes 
comunidades o en las heterogéneas opiniones de los filósofos; resulta preferible empezar a construir desde cero y con un único plan racional a partir del propio entendimiento. No es extraño, pues, que el Discurso del método cartesiano no contenga más que alguna velada alusión a los filósofos escolásticos y alguna cita referencial a algún científico contemporáneo (por ejemplo, Harvey), con el propósito de aportar evidencia nueva a las teorías del filósofo. Las palabras prestadas desaparecen de este manifiesto del monologismo racionalista, como ocurrirá también en ese monumento de la razón geométrica que es la Ética de Spinoza. Pero esta neutralización de la intertextualidad del texto filosófico no es exclusiva del racionalismo continental, ya que forma parte del estilo argumentativo de todo ese filosofar moderno que ha optado por el universalismo abstracto y la demostración lógica, en desmedro de los discursos locales y las voces tradicionales. En semejante contexto, no sorprende que Francis Bacon, al tratar de reconstruir un nuevo sistema del razonamiento humano basado la experimentación y en una rigurosa lógica inductiva, repudiase los préstamos discursivos y las opiniones recibidas de los filósofos, como si únicamente constituyeran obstáculos imaginarios para el avance de las ciencias, es decir, simples ídolos provenientes del foro de los intercambios verbales o del teatro de las opiniones filosóficas (Cfr. Bacon, 1949: 84-87).

Aunque con frecuencia se generaliza a toda la modernidad el monologismo racionalista y el universalismo abstracto del discurso de la nueva ciencia, lo cierto es que en la primera modernidad se exploraron otros modos de escritura y de lectura mucho más propensos a la incorporación de otras voces discursivas y de palabras prestadas. En los ensayos filosóficos de los humanistas del Renacimiento, vemos perfilarse un tipo texto profusamente sembrado de citas eruditas, y que rinde todos los honores a las voces filosóficas de la Antigüedad. Si revisamos los Ensayos de Montaigne, podremos apreciar una llamativa riqueza intertextual, que no solo depende de la cantidad y calidad de las citas (esto es, del nutrido repertorio de voces filosóficas o literarias que resultan convocadas en su lengua originaria), sino también de un tipo de relación profundamente autoconsciente con las fuentes textuales, las voces clásicas grecolatinas y los mundos literarios y filosóficos de la Antigüedad. En algunos de sus ensayos, Montaigne (2004) teje el texto como una serie de comentarios personales y de ocurrencias subjetivas a partir de citas literales de Cicerón, Séneca, Julio César, Plutarco o Virgilio, entre otros muchos. En este uso de la citación no se pretende invocar la autoridad de los antiguos ni apelar a los nuevos descubrimientos de los 
contemporáneos, sino que se hace de la cita un pretexto para la apropiación subjetiva y el autodescubrimiento personal. Montaigne carga con el peso de numerosas voces ajenas, las trasplanta en el solar de su propia escritura, pero también se oculta y disfraza con las fuentes que cita. Al citar, parece más preocupado del estilo ameno y elegante de los clásicos, que de sus proposiciones temáticas; está más interesado en la personalidad de quien se cita, que en lo que presuntamente le enseñan sus afirmaciones. En ese sentido, la erudita citación que Montaigne despliega está puesta al servicio de la autoexploración personal de quien lee y escribe, y el ensayista tiene muy claro que, al tomar palabras prestadas de otros, está dando forma a su propia subjetividad y al conocimiento de sí mismo. El formato de cita de los Ensayos de Montaigne combina la referencia intertextual a los clásicos, con el posicionamiento metadiscursivo frente a lo que se cita y, finalmente, con la exhibición de los aspectos estilísticos singulares del material referenciado. De esa manera, la cita ensayística explora una recontextualización de los textos clásicos, al servicio de la apropiación personal y de la apertura de nuevos marcos de entendimiento con los lectores, siempre desde la perspectiva subjetiva del autor. Con todo, la subjetividad moderna no se autodescubrió en el vacío, sino que también se conformó intertextualmente al citar voces ajenas y palabras prestadas.

Ahora bien, el uso de la cita al servicio de la crítica de fuentes y de la investigación históricamente informada solo se consolidó en la época de la Ilustración, cuando la libre circulación de escritos en la esfera pública, la razonable discusión de los públicos letrados, pero también los nuevos modos de lectura críticos y desacralizados, fueron consagrados como horizonte histórico ideal y motor del progreso. En la República de las Letras que así se esbozaba, cobró pleno sentido la revisión de los prejuicios heredados y de los errores de interpretación tradicionales, por medio de la investigación crítica de las fuentes. Uno de los principales promotores de esta apuesta por la difusión de las luces y letras de la razón es Pierre Bayle, autor clave en la defensa de la tolerancia religiosa y en la extensión de la Ilustración en la Europa del siglo XVIII. En su Diccionario histórico y crítico (publicado originalmente entre 1695 y 1697), Bayle introdujo una compleja forma de organización del texto, en la cual cada entrada tiene asociado todo un subtexto, que estaba conformado por el extenso aparato de notas a pie de página que comentan el texto principal, enmarcadas por otras citas o por referencias bibliográficas numeradas que indicaban las fuentes citadas. De ese modo, el texto de la entrada se reducía al mínimo, dentro de este marco de notas críticas a pie de 
página, repletas de citas que ponderaban los méritos de las opiniones de otros comentaristas y filósofos. En este formato de citación vemos desplegarse un nuevo tipo de referencia crítica, al servicio de la contrastación e investigación de las fuentes, y que ya no se limita a la confirmación de los argumentos por la autoridad, o a procurar el reconocimiento de los lectores en torno a un saber enciclopédico compartido y a un repertorio común de autores. Como sustento de esta triangulación crítica de las fuentes citadas, Bayle establece un sistema de citación jerarquizado, en el cual encontramos algunas citas directas o indirectas ya en la propia entrada enciclopédica, aunque la mayoría de las citas textuales extensas se hallan en el aparato de notas a pie de página; finalmente, en las notas marginales numeradas, accedemos a citas adicionales o podemos revisar referencias bibliográficas de las fuentes citadas (Bayle, 2010). Así, pues, la citación se conforma como un paratexto que circunda al texto principal y lo atraviesa con numerosas reservas críticas y orientaciones bibliográficas. En ese sentido, la cita crítica constituye una encrucijada entre la función intertextual de la cita como incorporación de otros discursos y, por otra parte, cierta función metadiscursiva de la citación como posicionamiento del autor ante los materiales citados, al aportar evidencias textuales que inducen a la ponderación de los argumentos y a la revisión de los prejuicios y malentendidos por parte de los lectores. En suma, esta propuesta de Ilustración no parece proyectar el monólogo abstracto de la razón consigo misma o la apropiación monológica de todas las opiniones indirectamente referidas y privadas de su textura; por el contrario, se trata de convocar críticamente las razones ajenas y de citar los argumentos de todos quienes participan de la República de las Letras.

En el curso del siglo XIX es posible reconocer algunas transformaciones en los formatos de citación filosófica, que posibilitaron la conformación, difusión y estandarización de sistemas de citación académicos, a partir de algunos de los desarrollos precedentes en las formas y funciones de la cita. El contexto de estas nuevas tendencias de la citación filosófica coincide con la reorganización de los saberes en torno a las universidades nacionales, las cuales se convertirían progresivamente en el órgano de la enseñanza superior (bajo el modelo de la Universidad de Berlín), al alero de nuevos relatos de legitimación de la actividad intelectual que apelan a una nueva convergencia entre investigación científica, Estado y nación. En ese sentido, la universidad alemana fue un modelo de organización de la actividad académica, que combinaba la formación intelectual de la nación y la autonomía espiritual del saber especulativo. Las ciencias del espíritu tuvieron un rol protagónico 
en este modelo formativo, de modo que se asistió a un notable desarrollo de las ciencias históricas y las humanidades. Este profundo interés en la investigación histórica, filológica y hermenéutica, aparece marcado por la necesidad de conservar cierta autocomprensión del Volksgeist, mediante la indagación de la lengua vernácula, la interpretación rigurosa de las tradiciones textualmente transmitidas y la historiografía metodológicamente disciplinada. En semejante contexto de inscripción universitaria del saber, la escritura académica se encuentra cada vez más enmarcada por la especialización de géneros textuales del tipo de la disertación, la tesis o el artículo, así como por la creciente formalización de las constricciones impuestas al texto disciplinar. Bajo ese influjo de la investigación filológica, histórica y hermenéutica, en el caso de la citación se refuerza la exigencia metodológica de una exhaustiva investigación crítica de las fuentes disciplinares y el requisito de incluir un aparato de referencias bibliográficas detalladas.

Cabe reconocer este formato de cita netamente académica en la tesis doctoral de Schopenhauer, presentada en 1813 con el título De la cuádruple raíz del principio de razón suficiente. Schopenhauer (1981) realiza una reconstrucción histórico-hermenéutica del principio de razón suficiente, e incluye tanto citas directas en idioma original (de Platón, Plutarco, Aristóteles, Ireneo, Suárez, Descartes, Spinoza, Leibniz, Wolf, Platner y Kiesewetter), cuanto citas indirectas y referencias a numerosos antiguos y modernos, sobre todo de la escuela kantiana. En efecto, llama la atención la alta proporción de referencias específicamente alemanas en el conjunto de las citas y referencias. En el capítulo en que Schopenhauer resume la historia del problema, cita a veintidós autores vinculados a la tradición germana (muchos de ellos contemporáneos) y a un poeta alemán como Schiller, mientras solo cita a nueve autores grecolatinos o del resto de Europa. Incluso, en autores tan idiosincráticos y díscolos como Schopenhauer, la citación filosófica parece estar enmarcada en el contexto de esa nueva corte académica al servicio de la legitimación del saber estatal-nacional; a la academia se le han de rendir deferencias (por medio de las referencias) si es que el intelectual pretende integrarse a tan selecta comunidad espiritual.

En todo caso, este tipo de cita académica no solo provee orientación en las distintas de redes intelectuales del saber disciplinar establecido, sino que además cumple una indiscutible función argumentativa y crítica, al exponer sistemáticamente las contribuciones de cada fuente al problema y las limitaciones de cada planteamiento. En ese sentido, la dimensión 
intertextual de la cita académica, o sea la apertura del texto a otras voces discursivas y a la textura singular de cada texto citado, parece estar subordinada al posicionamiento metadiscursivo del autor frente a aquello que cita y a la integración sistemática de las fuentes en el metadiscurso del filósofo. Encontramos un ejemplo más consolidado de este tipo de citación académica en la tesis de magister de Kierkegaard, Sobre el concepto de ironía, defendida en 1841 en la Universidad de Copenhage. Nuevamente, asistimos a un ejercicio académico de reconstrucción histórico-hermenéutica en que son citadas directa e indirectamente las principales fuentes clásicas griegas y contemporáneas (fundamentalmente filósofos alemanes) del problema investigado en la tesis, las diferencias entre la ironía socrática y la romántica. Una vez más, la integración sistemática de las fuentes investigadas en el metadiscurso del autor (y en las frecuentes digresiones de quien escribe) prima sobre la apertura intertextual a otras voces discursivas, aunque el texto de Kierkegaard (2000) contiene más citas literarias que exponen la singular textura poética de algunos textos, con un propósito netamente estético. Pero lo más interesante de las prácticas de citación de la tesis de Kierkegaard es que responden a un formato de cita académica altamente formalizado, con un cuidadoso manejo de las fuentes textuales, una precisa indicación de las referencias bibliográficas, así como una sofisticada inscripción jerárquica de las citas en el cuerpo del texto y en el aparato de notas a pie de página. En fin, pese a que a su tesis se le observó un tono poco serio, hasta un autor tan singular como Kierkegaard le rinde honores a ese modo de citación académica que se consagró en la investigación histórico-hermenéutica del siglo XIX y que enmarcaría el formato de la cita hasta el siglo XX.

Al recorrer la historia de los formatos de citación en la escritura filosófica moderna no es difícil reconocer un esbozo anticipado del complejo repertorio de formas y funciones de la cita en el discurso filosófico contemporáneo. Los distintos tipos de remisión citacional que atraviesan el discurso filosófico de la modernidad también surcan, cruzan y difractan los textos de la filosofía contemporánea; la filosofía del siglo XX también se expone a la tensión entre una citación que permite el posicionamiento e integración metadiscursiva $\mathrm{y}$, por otra parte, una citación netamente intertextual, que abre el texto a otras voces discursivas y hace comparecer en la escritura la textura singular de otros textos, a menudo poéticamente. Sin embargo, pese a que nos encontramos con algunos ejercicios de reinvención vanguardista del injerto citacional, como en el caso de los textos de Derrida (en consonancia con un proyecto de lectura y escritura que pretende exponer la intertextualidad 
ilimitada), actualmente se ha consolidado la especialización académica de la escritura filosófica y la normalización disciplinar del discurso de la filosofía, incluidas las normas de citación y el modo de organización de las referencias bibliográficas. En ciertos casos, incluso se puede observar que el estilo de los géneros discursivos más académicos, como la disertación o la tesis, ha trascendido a la escritura filosófica dirigida a públicos más amplios, de manera que algunas obras claves del pensamiento contemporáneo se encuentran repletas de citas directas e indirectas, con un aparato de notas a pie de página sumamente cuidado y un repertorio abrumador de referencias bibliográficas. Por otra parte, se observa cierto acercamiento de las publicaciones de filosofía a los formatos de citación altamente estandarizados de las ciencias sociales (como el formato de la American Psychological Association) que, cada vez en mayor medida, desincentivan las digresiones en notas a pie de página y privilegian las citas referenciales con el autor y el año entre paréntesis.

En suma, podría reconocerse cierta deriva del texto filosófico contemporáneo hacia modos de manejo de la citación cada vez más lineales y monológicos, disciplinarmente estandarizados, meramente referenciales y obsesionados por la cantidad de citas dadas y recibidas. Se trata de una tendencia que va de la mano con la importancia que tienen el impacto bibliométrico y la cantidad de citas recibidas, tanto para la determinación de la calidad de una publicación, como para la carrera profesional de un académico (destino habitual del filósofo contemporáneo promedio). En efecto, las revistas, los artículos y los filósofos se jerarquizan actualmente de acuerdo con un índice de calidad que está dado por el impacto bibliométrico; las redes disciplinares y los núcleos temáticos de la filosofía contemporánea se tejen en virtud de las referencias recíprocas entre artículos y autores. En ese sentido, Latour (Cfr. 1992: 38-44) sostiene que la construcción retórica de los hechos científicos tiene lugar cuando su inscripción en un artículo, que cita a cierto número de aliados en el campo, resulta aceptada al ser citada frecuentemente por otras publicaciones; nosotros podríamos concluir que, en la filosofía contemporánea, los asuntos y trayectorias de la filosofía (por no decir la cosa misma del pensar) se deciden en un juego semejante de atesoramiento de citas otorgadas y recibidas. Esta economía bibliométrica, que opera al servicio de la conversión y acumulación del capital simbólico obtenido a través del valor de cambio de la citación, no solo está muy lejos del tipo de intertextualidad disruptiva y subversiva cuya posibilidad entrevieron los teóricos post-estructuralistas. Además, nos separa definitivamente del dialogismo constitutivo que alguna vez caracterizó al discurso filosófico, 
como palabra mediadora que daba cabida a diferentes voces discursivas y nos invitaba a realizar la experiencia dialéctica de atender a las interpelaciones ajenas y hacer comparecer las razones discursivas de otros.

\section{Conclusión: por una retórica de la alteridad}

LA CONSOLIDACIÓN DE LOS ÍNDICES BILIOMÉTRICOS como mecanismo de validación de los textos filosóficos implica cierto triunfo de una retórica netamente instrumental, que solo procura cierto efecto persuasivo al aumentar la eficacia comunicacional de la escritura y la maximización del impacto en el público de lectores. Lo curioso es que este tipo de estrategia retórica instrumental (centrada en la capitalización de las citas bajo sistemas de citación estandarizados) neutraliza su propio carácter retórico: no solo se desincentiva la digresión discursiva o la estilización de la escritura, sino que, además, se atribuye el efecto persuasivo a una suerte de selección natural de los textos más referidos. De esa manera, la antigua retórica técnica, que se preocupaba de establecer las pautas de composición y estilo más eficazmente persuasivas, encuentra cierta continuidad en los manuales de estilo de escritura académica y en sus normas de citación. La retórica instrumental de los manuales de escritura académica constituye, pues, la continuación de la retórica técnica por otros medios, los medios neutralizados de un tipo de composición y selección textual que se pretende libre de apuestas retóricas.

Con la extensión de la retórica instrumental que subyace a la regulación del estilo disciplinar bajo la presión de los índices de impacto, no solamente se pone en entredicho el lugar de la retórica filosófica, ese tipo de retórica antigua vinculada a la contrastación y verificación dialéctica, esa retórica fundamentalmente preocupada de los medios de validación del argumento. La pérdida quizá más irreparable de cuantas se esbozan con la colonización bibliométrica del discurso filosófico consiste en que tal vez veamos desvanecerse la textura polifónica de algunos tipos de escritura filosófica que exhibieron la diversidad de las voces del mundo de vida socio-histórico, e hicieron comparecer las texturas discursivas singulares de las tradiciones transmitidas. En ese sentido, resulta urgente rescatar uno de los principales aportes de la tradición retórica occidental a los modos de argumentación pública, a saber: la atención a los registros singulares y a las situaciones contingentes de la enunciación; la asunción del carácter local de nuestros argumentos y auditorios, así como la interpretación circunstancial de nuestras pretensiones de validez y de los discursos que tomamos prestados. Una 
retórica a la altura de esas tareas no puede conformarse con reproducir los propósitos de la retórica técnica (la maximización del impacto persuasivo), ni tiene que limitarse a los presupuestos tradicionales de una retórica filosófica (asistir a la validación del logos e integrar sistemáticamente las distintas pretensiones de validez en un metadiscurso filosófico comprehensivo). Cuando la intertextualidad resulta bibliométricamente capitalizada y cuando la polifonía aparece instrumentalizada al servicio de la argumentación lineal y monológica, se hace más preciso que nunca cultivar una retórica de la alteridad, que atienda a la diferencia de las voces discursivas y a los cruces intertextuales de nuestros discursos, y nos permita enriquecer comparativamente las palabras prestadas con las cuales hablamos.

\section{Referencias}

Allen, G. (2000). Intertextuality. London: Routledge.

Aristóteles. (2001). Retórica. Madrid: Alianza Editorial.

Aristóteles. (2000). Metafísica. Madrid: Gredos.

Bacon, F. (1949). Novum Organum. Buenos Aires: Losada.

Bajtín, M. (1982). Estética de la creación verbal. México D. F.: Siglo XXI.

Barthes, R. (1994). El susurro del lenguaje. Barcelona: Paidós.

Bayle, P. (2010). Diccionario histórico y crítico. Buenos Aires: El cuenco de plata.

Brandist, C. (2002). The Bakhtin Circle. Philosophy, Culture and Politics. London: Pluto Press.

Burton, R. (2008). Anatomía de la melancolía. Madrid: Alianza Editorial.

Connors, R. J. (1998a). The Rhetoric of Citation Systems, Part I: The Development of Annotation Structures from the Renaissance to 1900. Rhetoric Review. Vol. 17, No. 1. (pp. 6-48).

Connors, R. J. (1998b). The Rhetoric of Citation Systems, Part II: Competing Epistemic Values in Citation. Rhetoric Review. Vol. 17, No. 2. (pp. 219-245).

Culler, J. (1976). Presupposition and Intertextuality. MLN. Vol. 91, No. 6. (pp. 1380-1396). 
Davidson, D. (2001). De la verdad y de la interpretación. Barcelona: Gedisa.

Derrida, J. (1989). Márgenes de la filosofía. Madrid: Ediciones Cátedra.

DerridA, J. (1975). La diseminación. Madrid: Fundamentos.

Descartes, R. (1984). Discurso del método. Madrid: Alianza Editorial.

Finnegan, R. (2011). Why Do We Quote? The Culture and History of Quotation. Cambridge: Open Book Publishers.

Foucault, M. (1985). Las palabras y las cosas. Barcelona: Planeta-Agostini.

Frege, G. (1984). Estudios sobre semántica. Barcelona: Orbis.

Gilbert, G. N. (1977). Referencing as Persuasion. Social Studies of Science. Vol. 7. (pp. 113-122).

Goodman, N. (1990). Maneras de hacer mundos. Madrid: Visor.

Grafton, A. (1999). The Footnote. A Curious History. Cambridge: Harvard University Press.

Holquist, M. (2002). Dialogism. Bakhtin and his World. London: Routledge.

KierkegaARD, S. (2000). Sobre el concepto de ironía. Escritos I. Valladolid: Trotta.

Kristeva, J. (1981). Semiótica I. Madrid: Fundamentos.

Latour, B. (1992). Ciencia en acción. Barcelona: Labor.

Montaigne, M. (2004). Ensayos completos. Madrid: Ediciones Cátedra.

Olson, D. R. (1999). El mundo sobre el papel. El impacto de la escritura y la lectura en la estructura del conocimiento. Barcelona: Gedisa.

Perelman, C., y Olbrechts-Tyteca, L. (1989). Tratado de la argumentación. Madrid: Gredos.

Platón. (1985). El Banquete. Fedón. Fedro. Barcelona: Labor.

Plett, H. (ed.). (1991). Intertextuality. New York: de Gruyter.

Ponzio, A. (1998). La revolución bajtiniana. Madrid: Ediciones Cátedra.

Quintiliano, M. F. (1916). Instituciones oratorias. Madrid: Imprenta de Perlado Páez y Compañía. 
Recanati, F. (2001). Open Quotation. Mind. No. 110. (pp. 637-687).

Rose, S. K. (1996). What's Love Got to Do with It? Scholarly Citation Practices as Courtship Rituals. Journal of Language and Learning across the Disciplines. Vol. 1, No. 3. (pp. 36-47).

Schopenhauer, A. (1981). De la cuádruple raíz del principio de razón suficiente. Madrid: Gredos.

Sokolowski, R. (1984). Quotation. Review of Metaphysics. Vol. 37, No. 4. (pp. 669-723).

Swales, J. (1986). Citation Analysis and Discourse Analysis. Applied Linguistics. No. 7. (pp. 39-56).

Voloshinov, V. (1976). El signo ideológico y la filosofía del lenguaje. Buenos Aires: Nueva Visión. 